\title{
Seroprevalence and determination of risk factors of HIV, HBV and syphilis in antenatal cases
}

\author{
Swathi B.K ${ }^{1}$, Prajna Sharma ${ }^{2, *}$ \\ ${ }^{1}$ Post Graduate, ${ }^{\mathbf{A}}$ Assistant Professor, Dept. of Microbiology, ${ }^{1}$ Rabindranath Tagore, Medical College, Udaipur, Rajasthan, ${ }^{\mathbf{2}}$ A.J. \\ Institute of Medical Sciences, Mangaluru, Karnataka, India \\ *Corresponding Author: Prajna Sharma \\ Email: drprajnasharma@gmail.com
}

Received: $12^{\text {th }}$ September, 2018

Accepted: $20^{\text {th }}$ September, 2018

\begin{abstract}
Introduction: Aim of the study was to determine the seroprevalance of HIV, HBS and Syphilis co-infection if any present and the associated risk factors in a tertiary care center of Mangaluru.

Materials and Methods: The study was conducted on 500 women attending antenatal checkups at A.J. Institute of Medical Sciences, Mangaluru. They were screened for HIV, HBV and Syphilis and were requested to provide socio-demographic and obstetric data following appropriate counselling and ethical clearance.

Results: The seropevalence of HIV, HBV infection and Syphilis were found to be $2.6 \%, 3.4 \%$ and $0.2 \%$ respectively. Low literacy levels, early initiation of sexual activity, low per capita income were the most commonly associated risk factors.

Conclusion: Sexually transmitted diseases and its complications are a significant part of health challenges the public face today. Most common among the sexually active group, it is a major issue among the reproductive age group as the infection can be transmitted vertically.
\end{abstract}

Keywords: HIV, HBV, Syphilis.

\section{Introduction}

The spread of Sexually Transmitted Diseases (STD) and the resulting morbidity are the major public health challenges and have adverse social and economic implications. The pregnant population serves as an important marker of the extent of the problem in sexually active population. In addition to this, high prevalence of STDs among pregnant women leads to prenatal transmission of the diseases which contributes to neonatal and infant mortality and congenital infections. STDs and their complications are among the five main causes involved in the use of health services in developing countries. ${ }^{1}$ Women are more vulnerable than men to STDs in biological, cultural and socioeconomic terms. STDs among pregnant women poses particular risk to their families, offspring and health workers at the time of delivery. ${ }^{2}$

HIV infection has emerged as the global health problem with serious medical, economic and social implications. ${ }^{3}$ HIV infection can be transmitted from infected mother to her fetus during pregnancy, delivery or by breast feeding. This is a highly potent form of transmission in developing countries, where the proportion of infected women to infected fetuses is 1:1. Virology analysis of aborted fetuses indicated that HIV can be transmitted to fetus as early as first and second trimesters of pregnancy. ${ }^{4} \mathrm{HIV}$ infection in pregnancy is associated with adverse maternal and fetal outcome. ${ }^{5}$

Hepatitis B virus (HBV) is the most common causative agent of transmission associated hepatitis. Human are the only reservoir of HBV. HBV infection can be transmitted vertically during pregnancy. Almost $10 \%$ of infants born to women with acute HBV infection during the first trimester of pregnancy are HBsAg positive and at birth $80-90 \%$ of neonates become HBsAg positive without prophylactic therapy if acute maternal infection develops during third trimester of pregnancy. ${ }^{6}$

Syphilis in adults and neonates is still a public health problem. Although pregnancy doesn't alter the clinical course of syphilis, early diagnosis during prenatal care is essential to prevent congenital infection and administer adequate treatment to the mother. ${ }^{7}$ Transmission of Treponema Pallidum from syphilitic women to her fetus through placenta may occur at any stage of pregnancy but the lesions of congenital syphilis generally have their onset after the fourth month of gestation, when fetal immunological competence begins to develop. This timing suggests that the pathogenesis of congenital syphilis depends on the immune response of the host rather than on the direct toxic effect of Treponema Pallidum. The risk of infection of the fetus during untreated early maternal syphilis is estimated to be $75-95 \%$, decreasing to approximately $35 \%$ in treated cases of maternal syphilis of 2 years duration. ${ }^{8}$

The present study was carried out at a tertiary care hospital with an aim to determine the seroprevalence of HIV, HBV and Syphilis in antenatal cases, to determine presence of any co-infection among above mentioned diseases and associated risk factors.

\section{Materials and Methods}

This is a cross-sectional study conducted in A J Institute of Medical Sciences and Research Centre, Mangaluru in the month of March 2017 to August 2017 to determine the prevalence of HBV surface antigen, 
antibodies to Treponema Pallidum and antibodies against HIV among pregnant women. The study duration was for six months. The study populations were the pregnant women during their firts visit to the antenatal clinic of the hospital of AJIMS. A sample size of 500 was tested for seroprevalence of HIV, HBV and syphilis.

The antenatal women were invited to participate in the study. After obtaining informed consent from them a questionnaire was provided which explored their biodata, obstetric history and clinical details significant for the study for determining the presence of risk factors of STDs.

A blood sample was drawn to test for HIV, HBV, and T. Pallidum infection as a part of routine prenatal care with pretest counseling. $5 \mathrm{~mL}$ of blood sample was collected using a sterile plain vacutainer and the serum was separated by centrifugation into sterile serum storage vials.

Laboratory test for HIV Antibodies: HIV antibodies were tested by three rapid tests of different principles as per the norms of National Aids Control Organization, India guidelines. ${ }^{9}$ These tests were screening tests and confirmatory tests followed in the hospital for Anti HIV-1 and HIV-2 and were for in vitro diagnostic use only. The three rapid tests were Immunochromatographic method (Pareekshak), Immunofiltration method (Aidscan) and Immunodot assay (Combaids rs).

Laboratory tests for HBsAg: The serum samples collected were checked for the presence of Hepatitis B Virus surface antigen using HBsAg enzyme Linked Immuno Sorbent Assay (ELISA) which is a direct noncompetitive solid phase enzyme immunoassay for the detection of HBsAg in serum or plasma.

III. Laboratory Tests for Syphilis: Serum samples from all antenatal women were tested for the presence of treponemal antibodies using cardiolipin antibodies. VDRL (Venereal Disease Research Laboratory) test is a macroscopic slide flocculation test for the detection and quantization of antilipoidal antibodies present in serum or plasma of syphilitic patient. Serum or plasma was mixed with the reagent and allowed to act for few minutes on VDRL slide. When antilipoidal antibodies were present in the specimen visible floccules were formed. VDRL reactive screening was followed by
TPHA (Treponema Pallidum Haemagglutination Assay) for confirmation.

\section{Statistical Analysis}

All the results of the study thus obtained were grouped according to the age as well as trimester. The total number of blood samples tested (500 in number); number of negative cases, number of positive cases, percentage $(\%)$ prevalence of the positive cases for each serology and $95 \%$ confidence interval was calculated for each prevalence rate. The mean, range and percentage were calculated for age and income. Mean age of first pregnancy was calculated and the distribution represented by a bar diagram. Other associated risk factors mentioned in the questionnaire were documented and percentage prevalence of each factor was determined. Co-infection among HIV, HBV and syphilis was also looked for and its prevalence rate was also determined. Percentage wise distribution of the antenatal population who participated in the study based on the infection status was done. Co-relation of various factors with the prevalence of STD was also looked for. Percentage prevalence of each factor was also calculated.

The result of the study thus obtained was compared with the results of other similar research works with antenatal women as their subjects for HIV and HBV and Syphilis as mentioned above. Thus reliability of the study was determined.

\section{Results}

A total of 500 antenatal patients visiting the antenatal clinic of A J Institute of Medical Sciences and Research Centre participated in the study during the

Month of March to August 2017, conducted to detect the seroprevalence and risk factor determination of HIV, HBV and Syphilis infections. The 500 samples were screened for HIV, HBV and Syphilis as a part of routine antenatal care. Following appropriate counseling they were asked to provide sociodemographic and obstetric data in the questionnaire provided to them on obtaining written consent.

The seroprevalence of the infections were as follows (Table 1).

Table 1: Age distribution of the infections and their \% prevalence and $95 \%$ confidence interval

\begin{tabular}{|c|c|c|c|c|c|c|c|c|c|}
\hline $\begin{array}{c}\text { Age (in years) } \\
\text { Infection }\end{array}$ & & $\mathbf{1 6 - 2 0}$ & $\mathbf{2 1 - 2 5}$ & $\mathbf{2 6 - 3 0}$ & $\mathbf{3 1 - 3 5}$ & $\mathbf{> 3 5}$ & Total & $\mathbf{\%}$ Prevalence & $\mathbf{9 5 \%}$ CI \\
\hline HIV & Positive & 1 & 3 & 5 & 1 & 3 & 13 & 2.6 & $1.2-3.9$ \\
\hline & Negative & 87 & 156 & 143 & 59 & 42 & 487 & & \\
\hline & Total & 88 & 159 & 148 & 60 & 45 & 500 & & \\
\hline & & & & & & & & & \\
\hline HBV & Positive & 3 & 4 & 3 & 2 & 5 & 17 & 3.4 & $1.8-4.9$ \\
\hline & Negative & 85 & 155 & 145 & 58 & 40 & 483 & & \\
\hline & Total & 88 & 159 & 148 & 60 & 45 & 500 & & \\
\hline
\end{tabular}




\begin{tabular}{|c|c|c|c|c|c|c|c|c|c|}
\hline Syphilis & Positive & 0 & 1 & 0 & 0 & 0 & 1 & 0.2 & $0.19-0.59$ \\
\hline & Negative & 88 & 158 & 148 & 60 & 45 & 499 & & \\
\hline
\end{tabular}

Table 2: Distribution of the infections according to their trimester

\begin{tabular}{|c|c|c|c|c|c|}
\hline $\begin{array}{c}\text { Trimester } \\
\text { Infection }\end{array}$ & I Trimester & II Trimester & III Trimester & Total \\
\hline HIV & Positive & $9(1.8)$ & $4(0.8)$ & 0 & $13(2.6)$ \\
\hline & Negative & 377 & 94 & 16 & 487 \\
\hline & Total & 386 & 98 & 16 & 500 \\
\hline & & & & & \\
\hline HBV & Positive & $10(2)$ & $7(1.4)$ & 0 & $17(3.4)$ \\
\hline & Negative & 376 & 91 & 16 & 483 \\
\hline & Total & 386 & 98 & 16 & 500 \\
\hline & & & & & \\
\hline Syphilis & Positive & $0(0)$ & $1(0.2)$ & 0 & $1(0.2)$ \\
\hline & Negative & 386 & 97 & 16 & 499 \\
\hline & Total & 386 & 98 & 16 & 500 \\
\hline
\end{tabular}

*( ) contain the percentage in 500 samples.

Table 3: Socio-demographic data

Table 3.1: Age during the current pregnancy

\begin{tabular}{|l|c|c|}
\hline Age (in years) & Frequency & Percentage (\%) \\
\hline $16-18$ & 12 & 2.4 \\
\hline $19-20$ & 56 & 11.2 \\
\hline $21-25$ & 179 & 33.8 \\
\hline $26-30$ & 162 & 32.4 \\
\hline $31-35$ & 60 & 12 \\
\hline$>35$ & 21 & 4.2 \\
\hline Total & 500 & 100 \\
\hline
\end{tabular}

\begin{tabular}{|l|c|}
\hline Mean & 25.45 years \\
\hline Range & $20(17-37$ years $)$ \\
\hline
\end{tabular}

Table 3.4: Marital status of the antenatal women

\begin{tabular}{|l|c|c|}
\hline Marital Status & Frequency & $\begin{array}{c}\text { Percentage } \\
(\%)\end{array}$ \\
\hline Single(not married) & 34 & 6.8 \\
\hline Married & 451 & 90.2 \\
\hline Separated/Divorced & 13 & 2.6 \\
\hline Widow & - & 0 \\
\hline Not reported & 2 & 0.4 \\
\hline Total & 500 & 100 \\
\hline
\end{tabular}

Table 4: Clinical data

\begin{tabular}{|l|c|}
\hline Mean & 24.10 years \\
\hline Range & $20(17$ to 37 years $)$ \\
\hline
\end{tabular}

Table 3.2: Literacy status of the antenatal women

\begin{tabular}{|l|c|c|}
\hline \multicolumn{1}{|c|}{ Literacy level } & Frequency & Percentage (\%) \\
\hline $\begin{array}{l}\text { Illiterate (able } \\
\text { to sign) }\end{array}$ & 4 & 0.8 \\
\hline $1-7^{\text {th }}$ & 92 & 18.4 \\
\hline $8^{\text {th }}-12^{\text {th }}$ & 267 & 53.4 \\
\hline$>12^{\text {th }}$ & 137 & 27.4 \\
\hline Total & 500 & 100 \\
\hline
\end{tabular}

\begin{tabular}{|c|l|}
\hline Range & Illiterate to post-graduation \\
\hline
\end{tabular}

Table 3.3: Family per capita income (According to modified BG Prasad's classification)

\begin{tabular}{|l|c|c|}
\hline $\begin{array}{c}\text { Income in rupees } \\
\text { per month }\end{array}$ & Frequency & $\begin{array}{c}\text { Percentage } \\
(\%)\end{array}$ \\
\hline$>5156$ & 279 & 55.8 \\
\hline $2578-5155$ & 108 & 21.6 \\
\hline $1547-2577$ & 70 & 14 \\
\hline $773-1546$ & 43 & 8.6 \\
\hline$<773$ & - & 0 \\
\hline Total & 500 & 100 \\
\hline
\end{tabular}

\begin{tabular}{|c|c|}
\hline Mean & 4843.4 Rupees \\
\hline Range & 1000-1200 Rupees/ Month \\
\hline
\end{tabular}




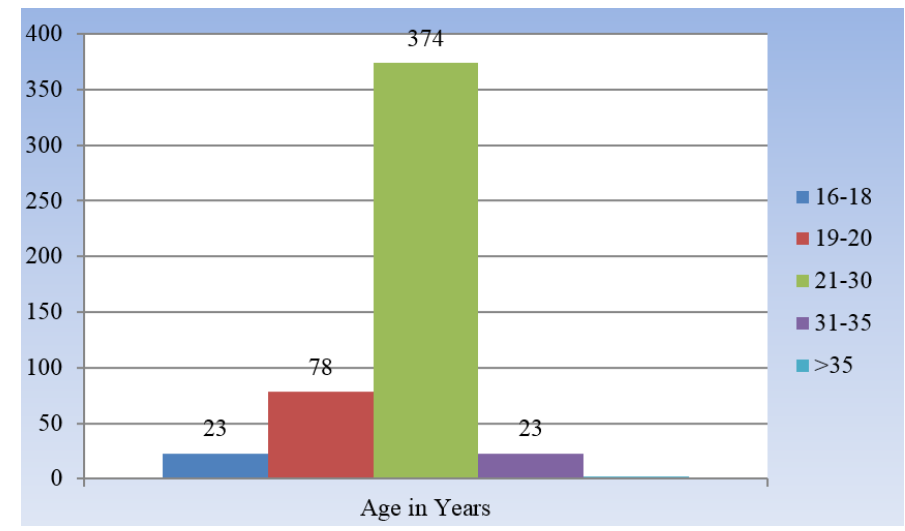

Fig. 1. Age at first pregnancy

Table 4.1: History of abortion/miscarriage

\begin{tabular}{|l|c|c|c|c|}
\hline \multicolumn{2}{|c|}{ Abortion/Miscarriage } & Frequency & \multicolumn{2}{c|}{ Percentage (\%) } \\
\hline None & 418 & \multicolumn{2}{|c|}{83.6} \\
\hline \multirow{2}{*}{$\begin{array}{l}\text { History of } \\
\text { abortion present }\end{array}$} & Spontaneous & 58 & 11.6 & 16.4 \\
\cline { 2 - 4 } & Induced & 24 & 4.8 & \\
\hline \multicolumn{2}{|l|}{ Total } & 500 & \multicolumn{2}{|c}{100} \\
\hline
\end{tabular}

Table 4.2: Reported history of sexually transmitted diseases (STDs)

\begin{tabular}{|l|c|c|c|c|}
\hline \multicolumn{2}{|c|}{ History of STDs } & Frequency & \multicolumn{2}{c|}{ Percentage (\%) } \\
\hline None & 424 & \multicolumn{2}{|c|}{84.8} \\
\hline Positive for STD & Previous & 41 & 8.2 & \multirow{2}{*}{15.2} \\
\cline { 2 - 4 } & Current & 35 & 7 & \\
\hline \multicolumn{2}{|l|}{ Total } & 500 & \multicolumn{2}{|c|}{100} \\
\hline
\end{tabular}

Table 4.3: Various factors contributing to HIV, HBV and Syphilis transmission (n=500)

\begin{tabular}{|l|c|c|}
\hline \multicolumn{1}{|c|}{ Factors* } & Frequency & Percentage (\%) \\
\hline Blood transfusion history & 78 & 15.6 \\
\hline Partner received blood transfusion & 69 & 13.8 \\
\hline Multiple Sexual partners & 38 & 7.6 \\
\hline HIV positive partners & 2 & 0.4 \\
\hline Partner with multiple sexual partners & 49 & 9.8 \\
\hline Body tattoos & 13 & 2.6 \\
\hline IV drug abuse & 0 & 0 \\
\hline History of Surgeries in the past (other than episiotomy/ C-section) & 34 & 6.8 \\
\hline
\end{tabular}

*Includes multiple responses

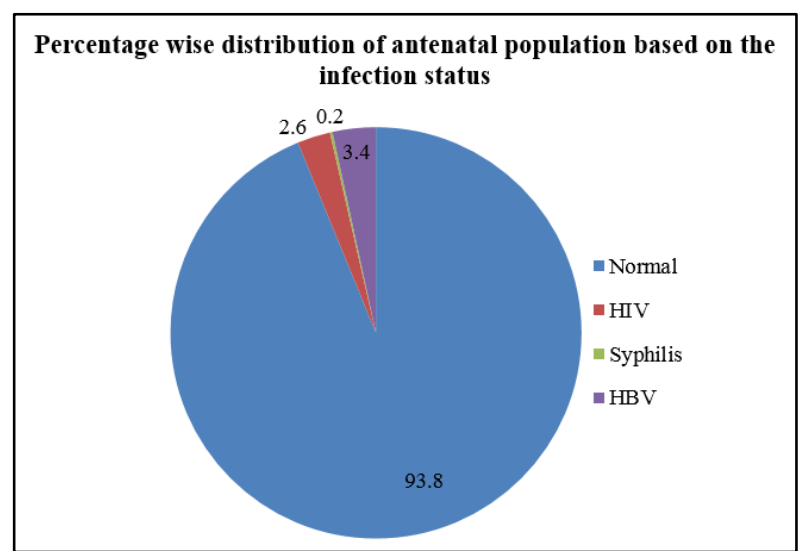

Fig. 2: Percentage distribution of antenatal samples based on study data 
Table 5: Comparison of various factors with the prevalence of STDs

Table 5.1: Prevalence of sexually transmitted diseases in antenatal women with history of multiple sexual partners

\begin{tabular}{|l|c|c|c|}
\hline \multirow{2}{*}{$\begin{array}{l}\text { Multiple Sexual } \\
\text { partners }\end{array}$} & \multicolumn{2}{|c|}{ History of Sexually Transmitted Diseases ()* } & \multirow{2}{*}{ Total } \\
\cline { 2 - 3 } & Yes & No & \\
\hline Yes & $21(4.2)$ & $17(3.4)$ & $38(7.6)$ \\
\hline No & $55(11)$ & $407(81.4)$ & $462(92.4)$ \\
\hline Total & $76(15.2)$ & $424(84.8)$ & 500 \\
\hline
\end{tabular}

Table 5.2: History of STDs with respect to marital status of the antenatal subjects

\begin{tabular}{|l|c|c|c|}
\hline \multirow{2}{*}{$\begin{array}{l}\text { Marital Status } \\
\text { married) }\end{array}$} & \multicolumn{2}{|c|}{ History of Sexually Transmitted Diseases ()* } & \multirow{2}{*}{ Total } \\
\cline { 2 - 3 } & Yes & No & \\
\hline Yes & $39(7.8)$ & $412(82.4)$ & $451(90.2)$ \\
\hline No & $37(7.4)$ & $12(2.4)$ & $49(9.8)$ \\
\hline Total & $76(15.2)$ & $424(84.8)$ & 500 \\
\hline
\end{tabular}

Table 5.3: History of STDs in relation to early age at first pregnancy

\begin{tabular}{|l|c|c|c|}
\hline \multirow{2}{*}{$\begin{array}{l}\text { Age at first pregnancy } \\
\text { less than 20 years }\end{array}$} & \multicolumn{2}{|c|}{ History of Sexually Transmitted Diseases ()* } & \multirow{2}{*}{ Total } \\
\cline { 2 - 3 } & Yes & No & \\
\hline Yes & $24(4.8)$ & $77(15.4)$ & $101(20.2)$ \\
\hline No & $52(10.4)$ & $347(69.4)$ & $399(79.8)$ \\
\hline Total & $76(15.2)$ & $424(84.8)$ & 500 \\
\hline
\end{tabular}

$*()$ contain the percentage in 500 samples.

There were 13 HIV positive samples out of 500 . Hence the overall percentage for HIV was $2.6 \%$ and 95\% CI 1.2-3.9 (Table 1). The seroprevalence of HIV was highest among the age group of 26-30 years (38.462\%). The least number of HIV positive antenatal women belonged to $16-20$ and 31-35 years of age with 1 positive sample in each category (7.69\%), however it is important to note that a women was already seropositve at a very young age of under 20 years . There were 9 positive samples for HIV in $1^{\text {st }}$ trimester and 4 in $2^{\text {nd }}$ trimester which accounted for $1.8 \%$ and 0.8 $\%$ respectively (Table 2 ).

There were 17 positive samples for HBsAg out of 500 , hence the overall prevalence rate was $3.4 \%$ and 95\% CI 1.8-4.9 (Table 1). The prevalence was high among pregnant women who were aged more than 35 years (5 out of 17 positive cases, $29.412 \%$ ) followed by women who aged between 21-25 years (4 out of 17 positive cases, $23.52 \%$ ) and the least belonging to 31 35 years of age ( 2 out of 17 cases, $11.76 \%$ ). However 3 samples of less than 20 age group also tested positive. 10 samples were $\mathrm{HBsAg}$ positive in $1^{\text {st }}$ trimester and 7 in $2^{\text {nd }}$ trimester with $2 \%$ and $1.4 \%$ prevalence (Table 2 ).

The incidence of Syphilis among the antenatal samples was insignificant as only 1 out of 500 was cases tested positive. The incidence rate was $0.2 \%$ and the $95 \%$ CI $0.19-0.59$ (Table 1 ). Thus only 1 sample of $2^{\text {nd }}$ trimester was positive belonging to 21-25 years of age group (Table 2). This case was associated with a positive history of blood transfusion during pregnancy.

Out of all 500 samples, no co-infection was found among HIV, HBV or Syphilis. Only isolated cases of these infections were reported. According to the data obtained $6.2 \%$ (31 out of 500) of the antenatal women were suffering from HIV, HBV or Syphilis during their current period of pregnancy (Fig. 2).

Table 3 (3.1, 3.2, 3.3, 3.4) describe the sociodemographic data and table $4(4.1,4.2,4.3,4.4)$ depict the clinical information obtained from the 500 antenatal participants. Table 3.1 shows the age at current pregnancy of the antenatal women. Maximum number of the women belonged to $21-25(33.8 \%)$ years of age and minimum to $16-18$ years $(2.4 \%)$. The mean age of pregnancy is 25.45 years with a range of 20 years. The literacy rate was $99.2 \%$ with most of them educated up to pre-university level (Table 3.2). According to the data mentioned in table $3.3,51.8 \%$ of the study subjects belonged to Class I of Modified BG Prasad's classification for socio-economic status. However their housing and property were not looked into. As given in table $3.4,34$ of the $500(6.8 \%)$ women who participated in the study were single. $13 \quad(2.6 \%)$ were divorced/separated.

Fig. 1 shows the distribution of antenatal samples based on the age at first pregnancy. As. It should be noted that 23 out of $500(4.6 \%)$ were pregnant by the age of 18 years. 76(15.2) were pregnant between 18-20 years. So, on the whole $19.8 \%$ of the women had early pregnancy. The mean age of first pregnancy was found to be 24years. As mentioned in table 4.1, $16.4 \%$ women gave a positive history for abortion/miscarriage. Table 4.2 gives the data regarding history of STDs. 15.2\% (76 subjects) of women gave a positive history for STD out of which $8 \%$ (41 out of 500) gave a past history and $7.2 \%$ (35 out of 500) gave a current history. Table 4.3 depicts various factors responsible for the transmission of STDs. 78 out of $500(15.6 \%)$ had a history of blood 
transfusion as a part of treatment to malaria and anemia. 7.6\% women had multiple sexual partners. 2 gave history of HIV positive partner. Body tattoos were found in $13(2.6 \%)$ individuals. 49 women had partners who had multiple sexual partner. $6.8 \%$ individuals had underwent surgeries in the past. Figure 2 shows the percentage wise distribution of the study participants based on their infection status.

Table 5 shows the relationship between various high risk behavior and history of STD. table 5.1 correlates the samples with multiple sexual partners with that of positive history of STD. Table 5.2 compares the marital status of the antenatal women with the history of STD. Table 5.3 relates the early age at pregnancy to history of STD.

The data in these tables present the probable risk factors responsible for the prevalence and transmission of HIV, HBV and Syphilis infections in sexually active population. Considering the prevalence of any STD, lack of adequate education, low socio-economic background, early sexual initiation, repeated abortions, blood transfusion, multiple sexual partners and partners with multiple partners were found to be more commonly associated factors.

Table 6.1: Comparison of percentage of positive subjects of HIV antibody among antenatal cases

\begin{tabular}{|l|}
\hline $\begin{array}{l}\text { Study Total Sample Percentage of positive } \\
\text { subjects }\end{array}$ \\
\hline Current study 5002.6 \\
\hline Mathur et al $\mathrm{l}^{[10]} 25501.86$ \\
\hline M.Mustafa et al ${ }^{[11]} 36021.1$ \\
\hline Gupta et al $\mathrm{l}^{[12]} 35290.88$ \\
\hline Mehta et al ${ }^{[13]} 10380.38$ \\
\hline
\end{tabular}

Table 6.2: Comparison of percentage of positive subjects of HBsAg among antenatal cases

\begin{tabular}{|l|}
\hline $\begin{array}{l}\text { Study Total Sample Percentage of positive } \\
\text { subjects }\end{array}$ \\
\hline Mittal et al $\mathrm{l}^{[14]} 8506.3$ \\
\hline Gill et al $^{[15]} 20005$ \\
\hline Nayak et al ${ }^{[16]} 85753.7$ \\
\hline Present study 5003.4 \\
\hline Mehta et a ${ }^{[13]} 10382.9$ \\
\hline Panda et $\mathrm{a}^{[17]} 84312.6$ \\
\hline Sehgal et al $\mathrm{l}^{[18]} 41372.6$ \\
\hline Gupta et al ${ }^{[12]} 23372.5$ \\
\hline Biswas et al $\mathrm{l}^{[19]} 10002.3$ \\
\hline
\end{tabular}

Table 6.3: Comparison of percentage of positive subjects of Syphilis among antenatal cases

\begin{tabular}{|l|}
\hline $\begin{array}{l}\text { Study Total Sample Percentage of positive } \\
\text { subjects }\end{array}$ \\
\hline Present study 5000.2 \\
\hline Mehta et al ${ }^{[13]} 10380.48$ \\
\hline Gupta et $\mathrm{al}^{[12]} 23371.47$ \\
\hline Kebede et al ${ }^{[20]} 4102.9$ \\
\hline
\end{tabular}

\section{Discussion}

Current study showed HIV seroprevalence of $2.6 \%$ which is much higher than the rates reported by Mathur et al $(1.86 \%),{ }^{10} \mathrm{M}$. Mustafa et al $(1.1 \%),{ }^{11}$ Gupta et al $(0.88 \%)^{12}$ and Mehta et al $(0.38 \%)^{13}$ (Table 6.1). This may be attributed to the prompt prenatal screening and excellent antenatal care provided in the clinic of A J Institute of Medical Sciences and Research Centre. Also considering the sample size and the number of elderly pregnant, and single women participated in the study, the rates might have soared up. However, the study indicates the increasing risk of HIV transmission, not only the pediatric age group but also among the sexually active population in the locality of Mangalore. One participant below 20 years was already HIV positive which reflects the seriousness of the problem and calls for immediate control and preventive measures. Though HIV infection doesn't have a cure it can be at least prevented for which appropriate prenatal screening of HIV plays a major role.

Out of the 500 samples 17 samples tested positive HBsAg and hence the prevalence rate was found to be $3.4 \%$. The results are in accordance those of Nayak et al (3.7) ${ }^{16}$ Mehta et al $(2.9 \%)^{13}$ and Panda et al $(2.6 \%) .{ }^{20}$ It is much lower compared to the results of Mittal et al $(6.3 \%),{ }^{14}$ and Gill et al $(5 \%)^{15}$ (Table 6.2). 3 under 20 years and 4 subjects of 21-25 years were HBsAg positive which meant they would live with chronic hepatitis if not for the routine screening procedure. Since vertical transmission is an important route of transmission of $\mathrm{HBV}$ infection, it is important to mandatorily test for HBV infection in pregnant women. Thus unsuspected chronic infective states can also be screened and patient can be referred for antiviral therapy. However, women above 35 years formed the major proportion of subjects suffering from Hepatitis B infection.

The Syphilis prevalence rate of $0.2 \%$ according to the present study is comparable with $0.48 \%$ rats of Mehta et $\mathrm{al}^{13}$ but very low compared to Gupta et al $(1.47 \%)^{12}$ and Kebede et al $(2.9 \%)^{20}$ (Table 6.3). With the development of antibiotic era and continued susceptibility of Treponema Pallidum to penicillin group of antibiotics without development of any resistance, the prevalence of Syphilis has rapidly come down in the last decade. However, few cases are reported here and there which still poses a threat of an outbreak. The current study came across a single case of Syphilis reported by a pregnant women belonging to $2^{\text {nd }}$ trimester accompanied with a positive history of blood transfusion. Also, with the increased usage of antibiotics and early detection of Syphilis and its prompt treatment studies pertaining to its detection are very limited in the recent times. Nevertheless, Syphilis remains to be an important STD that can cause congenital anomalies and dreaded complication such as neurosyphilis, stroke, meningitis, syphilitic aneurysm, increased risk of HIV infection and pregnancy and 
delivery related complication. All of this can be prevented by a simple screening procedure and treatment on time.

Prevalence of STDs was found to be associated with low educational status, poor socio-economic condition and early initiation of sexual activity. It was also noticed that history of STDs was present among married subjects who had sexual activity only with their spouse and no other sexual behavior. $55.26 \%$ of women with multiple sexual partners gave positive history of STD which invokes the association between the conditions. 72\% (55 0n 76) of the participants with history of STD had no multiple sexual partners which brings into picture the other routes of transmission of STDs such as blood transfusion, body tattoos, partners with multiple partners, IV drug abuse, surgical instrument injuries, needle prick injuries etcetera. Also, there was a strong association between early age at first pregnancy and history of STDs.

Though the associated risk factors were studied, due to the small sample size the study could not demonstrate any casual association between the factors and the infections. However, pertaining to the current study some of the factors that were more commonly associated with the infections and probably increased the likelihood of these infections were low literacy level, poor socio-economic conditions, early sexual initiation, blood transfusion, multiple sexual partners, history of previous STDs and partner with multiple sexual partners.

Studying prevalence rates and risk factors in antenatal population is useful because, the inference can be implemented on the general population who are sexually active. In his study $6.2 \%$ of the participants (31/500) presented with any current infections of HIV, HBV or Syphilis. Though appropriate screening methods and prophylactic measures are available vertical transmission remains an important and preventable route of transmission of these diseases. In spite of efforts from government for improved maternal and child care, the number of pregnant females attending antenatal checkups and counseling at the earliest still remains to be a meager proportion. Current study retrospectively shows the efficiency of antenatal care and screening and the level of health education regarding the same in the antenatal population. Also the screening programs have been effective in detecting these diseases.

\section{Conclusion}

Current study reaffirms the necessity of serologic screening tests as a part of antenatal care. This data helps health personnel to obtain a better picture of the prevalence of vertically transmitted diseases and adopt adequate appropriate therapeutic or prophylactic measures to prevent or manage them. The data also stresses the need for improved effective preventive programs for community at large, which could lead to decrease in the incidence of HIV, HBV and Syphilis. It also enlightens us about the increasing risk of HIV and HBV infections. Association of early pregnancy, low literacy level and occupational risk among the single women are also depicted in the study. Despite initiation from government and WHO for women empowerment, early pregnancy, lack of proper education, low socioeconomic conditions forcing them to get into prostitution at a very young age continues to remain a major problem in our country. At any rate, many more studies are necessary to assess the importance of various risk factors for specific serology. Health education and promotion should be carried out in the community to promote the women of our society to actively undergo prenatal checkups and counseling regarding the diseases and take timely treatment. Continuing efforts to strengthen the existing health education program and comprehensive screening for all pregnant women are necessary to prevent mother-tochild transmission of HBV, HIV and Syphilis.

\section{Acknowledgement}

Authors would like to thank Mrs. Manjula, Lecturer of Biostatistics, A.J. Institute of Medical Sciences, Mangaluru, Karnataka, India for analysis of data.

\section{References}

1. World Health Organization. Global prevalence and incidence of selected curable sexually transmitted infections: Overview and estimates. Geneva: World Health Organization; 2001.

2. Egesie UG, Mbooh RT. Seroprevalence of human immunodeficiency virus (HIV) infection in pregnant women in Amassoma. Nigeria. Afr J Biomed Res. 2008;11:111-113.

3. Chwee LC, Eke-Huber E, Starr E, John RE. Nigerian college students: HIV knowledge, perceived susceptibility for HIV and sexual behaviours. Coll Stud J. 2005;39:60-70.

4. Kasper L, Brawnwald E, Fauci A, Hauser S, Longo D, Jameson JL (2005) Harrison's Principles of Internal Medicine, 16th edition. Newyork, McGraw-Hill, Medical Publishing Division, p 2607.

5. Mclytyre J. Mothers infected with HIV reducing maternal deaths and disability during pregnancy. Brit Med Bull. 2003;67(1):127-135.

6. Sweet RL. Hepatitis B Infection in Pregnancy. Obstet Gynecol Report. 1990;2:128.

7. Seffield JS, Wendel Jr G.D. Syphilis in pregnancy. Clin Obstet Gynecol. 1999;42:97-106.

8. Kasper L, Brawnwald E, Fauci A, Hauser S, Longo D, Jameson JL (2005) Harrison's Principles of Internal Medicine, 16th edition Newyork. McGraw-Hill, Medical Publishing Division, p 2607.

9. Operational Guidelines for HIV Sentinel Surveillance, October 2007:National AIDS Control Organization Ministry of Health and Family Welfare Government of India.

10. Mathur M, Taklikar S, Turbadkar D. Study of HIV Seroprevalance and Sociodemographic in antenatal cases and vertical transmission to neonates. Indain J Med Microbiol. 2008;26:289-290. 
11. Mustafa M, Ahmed K S, Habibullah C M. Prevalence of Human Immunodeficiency Virus Infection in Pregnant Women. Indian J Med Microbiol. 2007;25:172-173.

12. Gupta S, Gupta R, Singh. Seroprevalance of HIV in Pregnant Women in North India: a tertiary care hospital based study. BMC Infectious Diseases. 2007;7:133.

13. Krunal D. Mehta, Sejul Antala, Madhulika Mistry, Yogesh Goswami: Seropositivity of hepatitis B, hepatitis $\mathrm{C}$, syphilis, and HIV in antenatal women in India. J Infect Dev Ctries. 2013;7(11):832-837.

14. Mittal SK, Rao S, Rastogi A, Aggarwal V, Kumari S. Hepatitis B, potential of perinatal transmission in India. Trop Gastroenterol 1996;17:190-192.

15. Gill HH, Majumdar PD, Dhunjibhoy KR, Desai HG (1995) Prevalence of hepatitis B e antigen in pregnant women and patients with liver disease. $J$ Assoc Physicians India. 1995;43:247-248.

16. Nayak NC, Panda SK, Zuckerman AJ, Bhan MK, Guha DK. Dynamics and impact of perinatal transmission of hepatitis B virus in North India. J Med Virol. 1987;21:137-145.

17. Panda SK, Ramesh R, Rao KVS, Gupta A, Zuckerman AJ, Nayak NC. Comparative evaluation of the immunogenicity of yeast derived (recombinant) and plasma derived Hepatitis B vaccine in infants. $J$ Med Virol. 1991;35:297-302.

18. Sehgal A, Gupta I, Sehgal R, Ganguly NK. Hepatitis B vaccine alone or in combination with anti-HBs immunoglobulin in the perinatal prophylaxis of babies born to HBsAg carrier mothers. Acta Virol. 1992;36:359366.

19. Biswas SC, Gupta I, Ganguly NK, Chawla Y, Dilawari JB (1989) Prevalence of hepatitis B surface antigen in pregnant mothers and its perinatal transmission. Trans $R$ Soc Trop Med Hyg. 1989;83:698-700.

20. Kebede E, Chamiso B. Prevalence of syphilis in pregnancy in Addis Ababa. East African Medical Journal. 2000;7:212-216.

How to cite this article: Swathi B.K, Sharma P. Seroprevalence and determination of risk factors of HIV, HBV and syphilis in antenatal cases. Indian $\mathbf{J}$ Microbiol Res. 2018;5(4):476-483. 